\title{
The case for a (geochemically) dirty mantle plume melange
}

\author{
OLIVER NEBEL ${ }^{1 *}$, GREG YAXLEY ${ }^{2}$ AND SASKIA \\ RUTTOR $^{3}$
}

${ }^{1}$ ISOTOPIA Laboratories, School of Earth, Atmosphere and Environment, Monsh University, Clayton 3800, VIC,

Australia, oliver.nebel@monash.edu

${ }^{2}$ RSES, The Australian National University, Acton 2601 ACT, Australia

Ocean Island Basalts (OIB - including more evolved lavas) are intra-plate lavas sourced from and thus sampling the upper mantle, with a possible connection to the lowermost mantle by rising mantle plumes. Their chemistry differs from those sampled at convergent and divergent plate margins, indicating that source material and/or processes forming them represent a unique global reservoir. The chemical diversity of OIB exceeds that of mid ocean ridge basalts (MORB), and radiogenic isotope systematics indicate the presence of enriched components of crustal origin. A wide spectrum of radiogenic and stable isotope studies of OIB has led to various models, which culminate in a scenario that favours the return of parts of subducted oceanic crust, in the form of eclogite, in mantle plumes, which rise from the deep in a primitive mantle-like matrix (termed FOZO). Among global OIB, the diversity in composition indicates a wide spectrum of enriched components (EM1, EM2, HIMU). A range of isolated (or combined) major and trace element, radiogenic and stable isotope studies point to clusters of enriched components that each relate to parts of the oceanic Penrose sequence or even sub-continental lithospheric mantle. However, depending on the tool employed, chemical and isotope proxies indicate that similar, enriched component clusters have seemingly different "origins". Furthermore, with convincing cases for subducted sediment $(\mathrm{EM} 1,2)$ and carbonatite (HIMU) as enriched mantle precurors, the questions arises: Where has all the basalt gone? A solution to this conundrum is provided through petrological experiments, which advocate that crustal lithologies, transformed under eclogite facies conditions, melt to form pyroxenites in ambient mantle. A model is suggested in which only melting products of subducted crust, their pyroxenite doppelgaengers, are present in melting zones in plumes. Forged during subduction in ambient depleted mantle coating the downgoing slab, these components are dragged down into the deep mantle to form a melange with primitive mantle. After plume entrainment and upon return to the shallow mantle, these dirty melanges then give rise to OIB. Maybe. 